\title{
Hypoglycemia Event Rates: A Comparison Between Real-World Data and Randomized Controlled Trial Populations in Insulin-Treated Diabetes
}

\author{
Lisa Elliott · Carrie Fidler · Andrea Ditchfield · Trine Stissing
}

To view enhanced content go to www.diabetestherapy-open.com Received: December 22, 2015 / Published online: February 17, 2016

(C) The Author(s) 2016. This article is published with open access at Springerlink.com

\begin{abstract}
Introduction: Hypoglycemia is the most common adverse effect of diabetes therapy, particularly insulin treatment. Hypoglycemia is associated with considerable clinical and economic burden, and may be under-reported. The aim of this study was to compare the frequency of hypoglycemic events reported in real-world settings with those reported in clinical trials.
\end{abstract}

Methods: We conducted a structured literature review in PubMed to identify hypoglycemic event rates in patients with type 1 diabetes mellitus (T1DM) and insulin-treated type 2

Electronic supplementary material The online version of this article (doi:10.1007/s13300-016-0157-z) contains supplementary material, which is available to authorized users.

L. Elliott · T. Stissing

Novo Nordisk A/S, Søborg, Denmark

L. Elliott

e-mail: le@novonordisk.com

C. Fidler $(\bowtie) \cdot$ A. Ditchfield

DRG Abacus, 6 Talisman Business Centre, Bicester, Oxfordshire, UK

e-mail: cfidler@teamdrg.com diabetes mellitus (T2DM) from real-world data (RWD) and randomized controlled trials (RCTs). The search was restricted to English language, full-text publications from 2010 onwards, reporting on treatment of T1DM or T2DM with basal only, basal-bolus, or premix insulin. Results: The final dataset included 30 studies (11 RWD studies and 19 RCTs). Six studies (RWD, $n=2$; RCT, $n=4$ ) reported hypoglycemia event rates in people with T1DM. For all reported categories of hypoglycemia (severe, non-severe, and nocturnal), rates were consistently higher in RWD studies compared with RCTs. Twenty-five studies (RWD, $n=10 ; \mathrm{RCT}, n=15$ ) reported hypoglycemia event rates in people with insulin-treated T2DM. For T2DM basal-oral therapy; the highest rates were observed in RWD studies, although there was an overlap with RCT rates. For basal-bolus therapy, there was considerable between-study variability but higher rates of severe and non-severe hypoglycemia were generally observed in RWD studies. For T2DM premix insulin, reported rates of hypoglycemia in RWD studies and RCTs were similar.

Conclusion: We found that higher rates of hypoglycemia are observed in real-world settings compared with clinical trial settings, 
although there is a large degree of overlap. Due to the inherent constraints of RCTs, they are likely to underestimate the burden of hypoglycemia in clinical practice. Further, high-quality RWD are needed to determine a more accurate incidence of hypoglycemia in clinical practice.

Keywords: Clinical trial data; Diabetes mellitus; Hypoglycemia; Hypoglycemia event rates; Insulin; Nocturnal hypoglycemia; Real world data; Severe hypoglycemia

\section{INTRODUCTION}

Diabetes is characterized by elevated blood glucose levels (hyperglycemia) and is associated with considerable morbidity and mortality [1, 2]. Good glycemic control with intensive treatment prevents or delays microvascular complications, and reduces cardiovascular and all-cause mortality [3, 4]. Therefore, a key clinical goal in the treatment and management of diabetes is to achieve good glycemic control with minimal hypoglycemia or other adverse effects of treatment. The recommended general glycemic target is a glycated hemoglobin $\left(\mathrm{HbA}_{1 \mathrm{c}}\right.$ ) level <7\% [5-7].

The most common and highly feared adverse effect of diabetes therapy, particularly insulin, is hypoglycemia, which occurs when the plasma glucose level becomes too low [8]. Hypoglycemia can occur suddenly and with varying severity. Severe events are categorized as those requiring the assistance of another person, whereas non-severe events do not require assistance [9-11]. Hypoglycemia has been shown to negatively impact on quality of life and productivity in the workplace $[10,12$, 13]. Fear of hypoglycemia can have a behavioral impact on diabetes management and metabolic control. To avoid hypoglycemia, patients may reduce or omit an insulin dose, which may result in sub-optimal glucose control and increase the risk of long-term complications $[14,15]$.

Hypoglycemia is not only associated with considerable cost to the individual in terms of wellbeing, it also represents a substantial cost burden to healthcare systems and society [16]. The total costs to the National Health Service, of managing non-severe and severe hypoglycemia in insulin-treated adults in the UK (population 64.1 million), were recently estimated at $£ 172.1$ million and £295.9 million per annum, respectively [17].

It can be difficult to accurately determine the frequency of hypoglycemic events due to differences in methods of data collection and the lack of a consistent clinical definition of hypoglycemia. Non-severe hypoglycemia is particularly underestimated as patients infrequently report these events to their physicians [18]. Randomized controlled trials (RCTs) remain the most reliable source of clinical evidence and are the gold standard for demonstrating clinical efficacy. However, the stringent constraints of a clinical trial setting, and the selection of patients enrolled, may limit the generalizability of RCTs to routine clinical practice. Other sources of evidence, such as real-world data (RWD), can be used to fill this gap and complement the available RCT evidence [19]. The use of RWD from sources such as databases, patient medical chart reviews and registries, and prospective and retrospective studies is increasingly being recognized as a valuable additional source of information to inform decision making and improve patient access to new drugs $[19,20]$. While there is no standardized definition of RWD, they are generally defined as data that are not collected in conventional RCTs [21]. RWD can provide the evidence for a treatment outside the tight 
constraints of a clinical trial setting, for example for patients excluded from trials, and patients whose treatment is determined by clinical practice rather than trial protocol. RWD can both complement and build on the evidence base established by RCTs and can be of particular benefit in the study of large, heterogeneous patient populations with complex, chronic diseases such as diabetes [22].

The aim of the current study was to compare the frequency of hypoglycemic events reported in real-world settings with those reported in clinical trials. A structured literature review was conducted to identify hypoglycemic event rates in patients with T1DM and T2DM using insulin in real-world settings and RCTs. This study was intended only as an observational analysis.

\section{METHODS}

A search was conducted in PubMed to identify published literature that reported hypoglycemic event rates in patients with T1DM and T2DM treated with insulin. The search was conducted on 9 December 2014 and was restricted to English language, full-text publications from 2010 onwards. The date restriction was to ensure that published hypoglycemia rates were reflective of current clinical practice. Search terms included diabetes mellitus, Type 1, T1DM, insulin-dependent diabetes mellitus, IDDM, Type 2, Type II, T2DM, non-insulin-dependent diabetes mellitus, NIDDM, glucose intolerance, hypoglycemia/ hypoglycaemia, randomized controlled trial, real world, observational, and insulin. No restrictions were placed on duration of diabetes or country. For RCTs, the minimum duration of studies of interest was 26 weeks, as previous insulin titration studies have shown that 26 weeks is sufficient for the majority of patients to reach a stable $\mathrm{HbA}_{1 \mathrm{c}}$ level $[23,24]$. Due to the nature of data collection in RWD studies, there was no restriction placed on duration. Studies of interest were restricted to those with total study populations $\geq 400$ patients; this was to ensure a large enough patient population for a reasonable estimation of severe hypoglycemia rates, without too great a restriction on the number of studies included in the final dataset [25]. Only studies that defined the diabetes population (i.e. T1DM or T2DM) and the insulin regimen (basal insulin only, basal-bolus, or premix) were included. Eligibility criteria for the studies of interest are shown in Table 1 . The original eligibility criteria for RWD studies specified any study reporting RWD, with the exception of case studies. However, a decision was made to exclude all database studies upon assessment of full text. This was because the majority of RWD database studies are based on insurance claim databases, where patients only tend to make a claim for incidences of severe and emergency-related hypoglycemic events, and thus, they do not provide an accurate representation of overall hypoglycemia in the real-world setting.

$\mathrm{HbA}_{1 \mathrm{c}}$ target and mean end-of-trial $\mathrm{HbA}_{1 \mathrm{c}}$ level were recorded, if reported, due to the relationship between $\mathrm{HbA}_{1 \mathrm{c}}$ levels and hypoglycemia risk.

\section{Hypoglycemia Definition}

For the purposes of this study, we considered three categories of hypoglycemia-severe, non-severe and nocturnal. Severe hypoglycemic events were defined as those that required the assistance of another person, and non-severe events as those that could be self-managed. Nocturnal events were simply defined as those that occurred after bedtime 
Table 1 Eligibility criteria for studies of interest

\begin{tabular}{ll}
\hline Eligibility criteria & Description \\
\hline Patient population & Adults with a diagnosis of T1DM or T2DM \\
& Receiving insulin treatment \\
Study design & RCT of any design (blinded/open-label): $\geq 400$ participants \\
& Any study providing RWD with the exception of case studies: $\geq 400$ participants \\
Study duration & RCTs: $\geq 26$ weeks (no restriction on duration was applied for RWD studies) \\
Intervention & Insulin treatment \\
& Basal only (irrespective of other combination oral therapies) \\
& Basal-bolus \\
& Premix \\
& Use of OADs alone was not permitted \\
& Hypoglycemia rates \\
& Overall, severe, non-severe (mild/moderate), nocturnal
\end{tabular}

$H b A_{1 c}$ glycated hemoglobin, NPH neutral protamine Hagedorn, $O A D$ oral anti-diabetic drug, $R C T$ randomized controlled trial, $R W D$ real-world data, TIDM type 1 diabetes mellitus, T2DM type 2 diabetes mellitus

and before the morning meal or insulin dose, to encompass the various definitions of the nocturnal period in the publications. A nocturnal event could be severe or non-severe. Although most studies reported severe hypoglycemia separately, some studies reported overall confirmed hypoglycemia rather than non-severe hypoglycemia, which could include all reported hypoglycemic events, both severe and non-severe. If non-severe hypoglycemia was not reported separately, confirmed hypoglycemia was considered representative of non-severe events for the purpose of this analysis, as the contribution of severe events had little impact on the overall rate. A small number of studies reported mutually exclusive groups of hypoglycemia; non-severe daytime, non-severe nocturnal and severe. Definitions of hypoglycemia used in each study are recorded in Supplementary Tables I-IV. Hypoglycemia event rates not reported as episodes per patient year (PPY) were converted to facilitate comparison.

This article is based on previously conducted studies and does not involve any new studies of human or animal subjects performed by any of the authors.

\section{RESULTS}

The original literature search identified 2171 potentially relevant studies. After removal of duplicates, 1974 citations were screened on the basis of title and abstract and any studies not meeting the inclusion criteria were excluded $(n=1750)$. A total of 224 full-text publications were assessed for eligibility whereupon a further 194 studies were excluded. Reasons for exclusion included: population $\leq 400$; RCT study duration $<26$ weeks; and hypoglycemia event rates not reported. The final included 


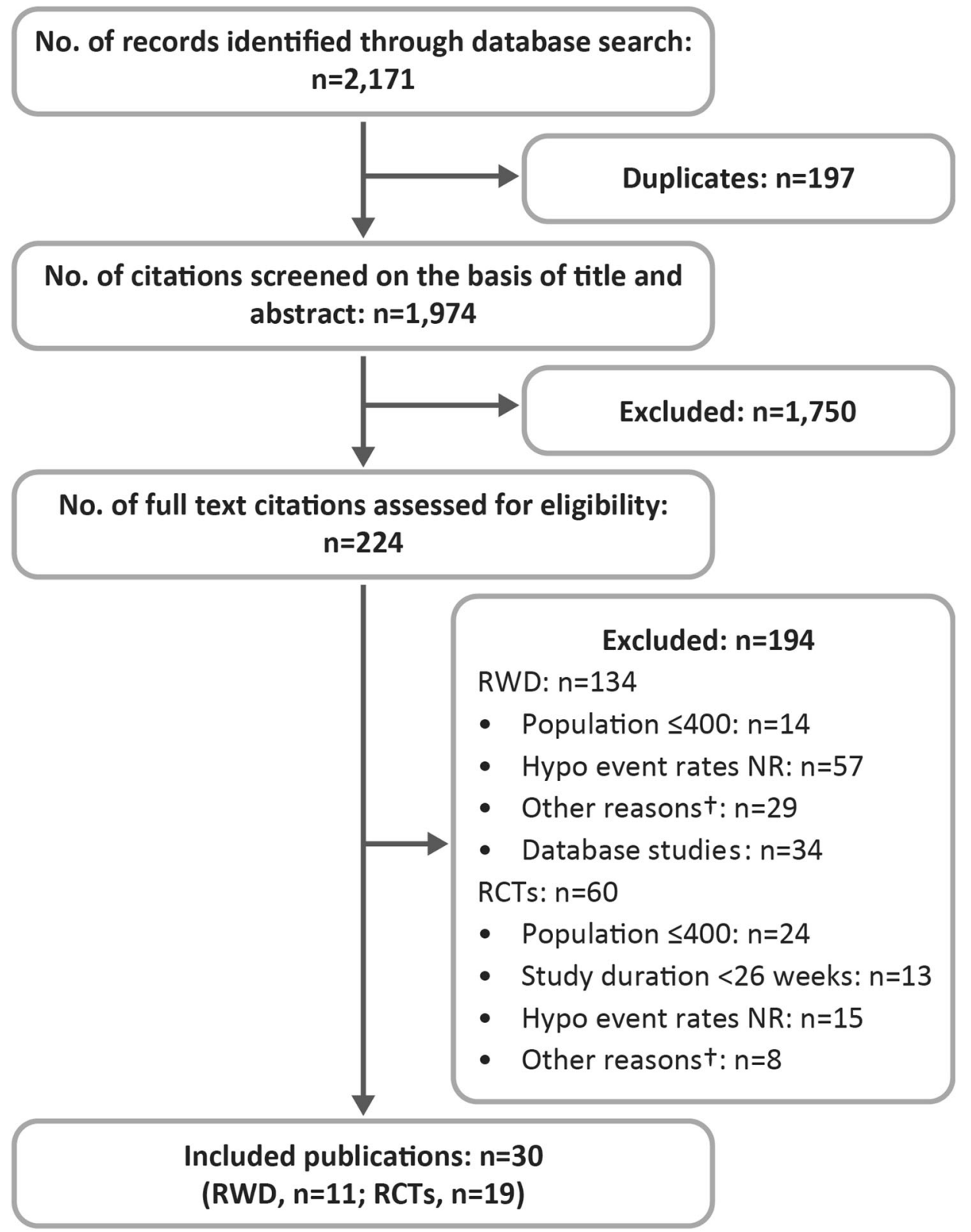

Fig. 1 Flow diagram of the literature search. Hypo hypoglycemia, $N R$ not reported, $R C T$ randomized controlled trial, $R W D$ real-world data. †Other reasons included type

dataset for analysis consisted of 30 studies, 11 RWD studies and 19 RCTs (Fig. 1).

The majority of RCTs identified in the literature search had a treat-to-target design whereby insulin doses are force-titrated to achieve a pre-specified glycemic target [26]. In general, $\mathrm{HbA}_{1 \mathrm{c}}$ targets were consistent across of diabetes not specified, insulin regimen not specified, study data reported elsewhere as part of a main study

RCTs with targets of $\leq 6.5 \%$ or $7.0 \%$ (Supplementary Tables I-IV).

Results are presented by diabetes population (T1DM, T2DM on basal-oral therapy, T2DM on basal-bolus therapy, and T2DM on premix insulin), as rates of hypoglycemia vary according to diabetes type/duration and 
insulin regimen. Studies will be represented more than once if they report on more than one diabetes population.

\section{T1DM}

Six studies (RWD, $n=2$; RCT, $n=4$ ) reported hypoglycemia event rates in people with T1DM [27-32]. For all reported categories of hypoglycemia (severe, non-severe, and nocturnal), rates were consistently higher in the RWD studies than the RCTs (Table 2; Supplementary Table I; rates are shown graphically in Fig. 2). Non-severe rates were 91.0 and 136.8 episodes PPY in the two RWD studies and 39.17-88.3 PPY in RCTs. Severe rates ranged from 0.7 to 1.59 episodes PPY in RWD studies versus (vs) $0.15-0.5$ episodes PPY in

Table 2 Summary of hypoglycemia event rates in RWD studies versus RCTs in patients with T1DM and in patients with T2DM according to insulin regimen

\begin{tabular}{|c|c|c|c|c|c|c|}
\hline \multirow{2}{*}{$\begin{array}{l}\text { Hypoglycemia } \\
\text { category }\end{array}$} & \multicolumn{3}{|c|}{ RWD studies } & \multicolumn{3}{|l|}{ RCTs } \\
\hline & $\begin{array}{l}\text { No. of } \\
\text { studies }\end{array}$ & $\begin{array}{l}\text { Hypoglycemia } \\
\text { event rates } \\
\text { episodes/patient/ } \\
\text { year (range) }\end{array}$ & References & $\begin{array}{l}\text { No. of } \\
\text { studies }\end{array}$ & $\begin{array}{l}\text { Hypoglycemia } \\
\text { event rates, } \\
\text { episodes/patient/ } \\
\text { year (range) }\end{array}$ & References \\
\hline \multicolumn{7}{|l|}{ T1DM } \\
\hline Non-severe/confirmed & 2 & $91.0-136.8$ & {$[30,32]$} & 3 & $39.17-88.3$ & {$[28,29,31]$} \\
\hline Severe & 2 & $0.7-1.59$ & {$[30,32]$} & 4 & $0.15-0.5$ & {$[27-29,31]$} \\
\hline Nocturnal & 1 & 20.0 & {$[32]$} & 4 & $3.71-10.0$ & {$[27-29,31]$} \\
\hline \multicolumn{7}{|c|}{ T2DM: basal-oral regimen } \\
\hline Non-severe/confirmed & 7 & $0.224-35.3$ & {$[32-38]$} & 10 & $0.286-16.4$ & {$[23,39-47]$} \\
\hline Severe & 6 & $0.000-0.12$ & {$[32-37]$} & 5 & $0.00-0.07$ & $\begin{array}{l}{[39,42,} \\
44-46]\end{array}$ \\
\hline Nocturnal & 6 & $0.277-13.4$ & {$[32,34-38]$} & 9 & $0.18-7.7$ & $\begin{array}{l}{[23,39,} \\
41-47]\end{array}$ \\
\hline \multicolumn{7}{|c|}{ T2DM: basal-bolus regimen } \\
\hline Non-severe/confirmed & 3 & $2.95-38.9$ & {$[32,37,38]$} & 4 & $9.28-26.6$ & {$[48-51]$} \\
\hline Severe & 2 & $0.00-0.2$ & {$[32,37]$} & 1 & $0.05-0.06$ & [49] \\
\hline Nocturnal & 3 & $0.42-8.5$ & {$[32,37,38]$} & 3 & $1.39-10.34$ & {$[48,49,51]$} \\
\hline \multicolumn{7}{|l|}{ T2DM: premix regimen } \\
\hline Non-severe/confirmed & 4 & $1.04-27.0$ & $\begin{array}{l}{[32,37,52,} \\
54]\end{array}$ & 5 & $7.08-20.8$ & $\begin{array}{c}{[39,48,50} \\
51,55]\end{array}$ \\
\hline Severe & 4 & $0.00-0.2$ & $\begin{array}{l}{[32,37,53} \\
54]\end{array}$ & 2 & $0.03-0.26$ & {$[39,55]$} \\
\hline Nocturnal & 4 & $0.20-7.3$ & $\begin{array}{c}{[32,37,52,} \\
54]\end{array}$ & 3 & $2.5-8.15$ & {$[39,48,51]$} \\
\hline
\end{tabular}

$\overline{R C T \text { randomized controlled trial, } R W D \text { real-world data, TIDM type } 1 \text { diabetes mellitus, T2DM type } 2 \text { diabetes mellitus }}$ 

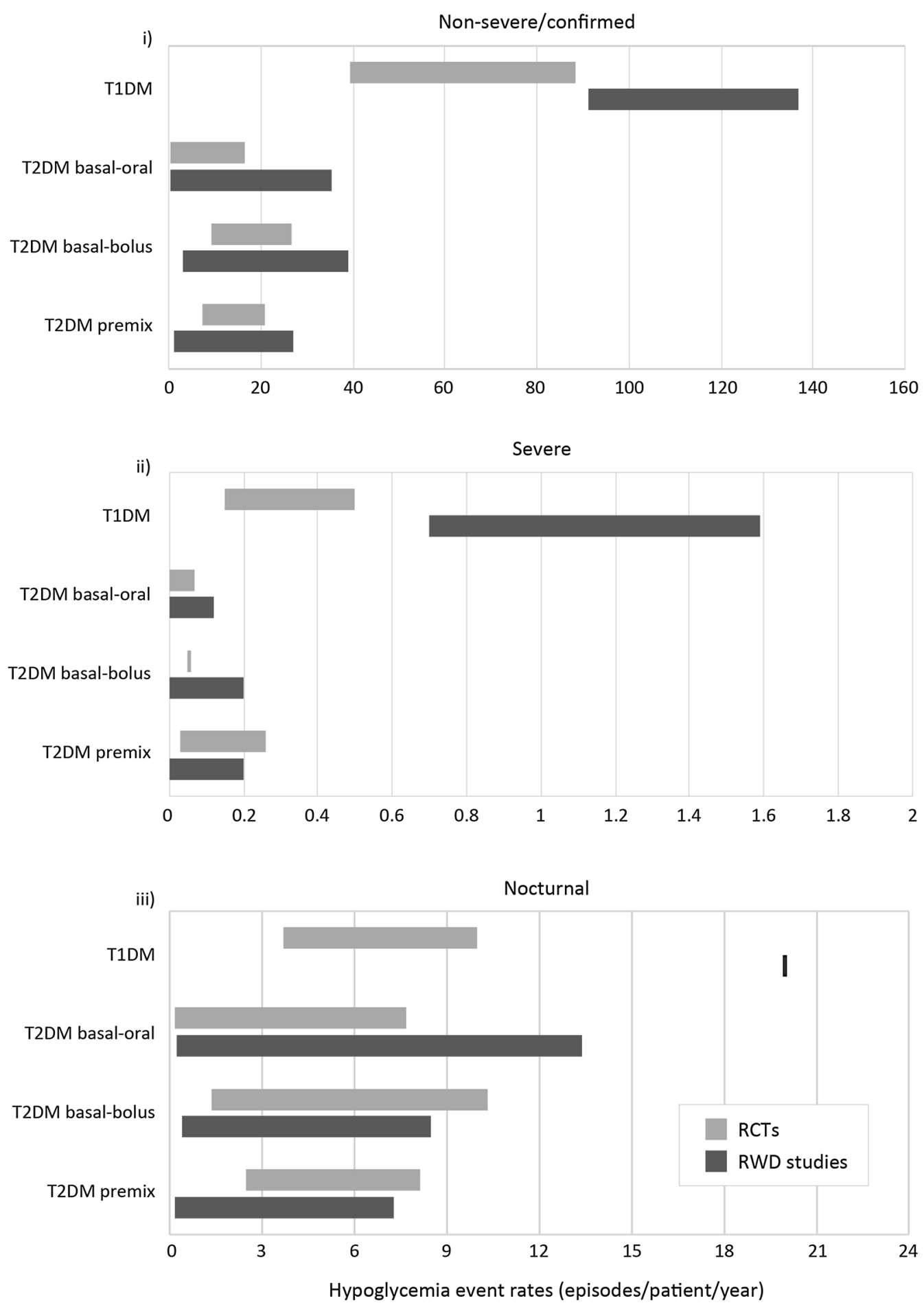

Fig. 2 Ranges of hypoglycemia event rates in RWD studies versus RCTs. Horizontal bars in $i$-iii show the ranges of hypoglycemia rates as summarized in Table 2. RCT randomized controlled trial, $R W D$ real-world data, TIDM type 1 diabetes mellitus, T2DM type 2 diabetes mellitus 
RCTs. The only nocturnal rate reported in RWD studies was 20.0 episodes PPY, vs 3.71-10.0 episodes PPY in RCTs. All four RCTs excluded patients with severe hypoglycemia or hypoglycemic unawareness. There was no consistent pattern between end-of-trial $\mathrm{HbA}_{1 \mathrm{c}}$ levels and hypoglycemia rates; however, the RCT by Mathieu et al. [31] had the highest rates of hypoglycemia (across all categories) and the lowest end-of-trial $\mathrm{HbA}_{1 \mathrm{c}}$ levels, at week 26 .

\section{T2DM}

Twenty-five studies (RWD, $n=10$; RCT, $n=15$ ) reported hypoglycemia event rates in people with insulin-treated T2DM. Hypoglycemia event rates in RWD studies and RCTs of patients with T2DM were compared according to the insulin regimen, i.e. basal-oral, basal-bolus, or premix regimen, as the risk of hypoglycemia in patients with T2DM rises with increasing duration of insulin therapy, and increasing complexity of insulin regimen [8].

\section{T2DM Basal-Oral Therapy}

Seven RWD studies [32-38] and 10 RCTs [23, 39-47] reported hypoglycemia event rates in people with insulin-treated T2DM receiving basal-oral regimens (Table 2; Supplementary Table II). There was variability in the rates of hypoglycemia across both RWD studies and RCTs for all hypoglycemia categories, and a large degree of overlap between the RWD rates and RCT rates. However, as for T1DM the highest rates across all categories of hypoglycemia were observed in the RWD studies (Table 2; Fig. 2). Non-severe rates of hypoglycemia ranged from 0.224 to 35.3 episodes PPY in RWD studies and from 0.286 to 16.4 episodes PPY in RCTs. Severe hypoglycemia rates ranged from 0.00 to 0.12 episodes PPY in RWD studies and from 0.00 to
0.07 episodes PPY in RCTs. Nocturnal confirmed event rates were 0.277-13.4 episodes PPY in RWD studies vs $0.18-7.7$ episodes PPY in RCTs. Non-severe nocturnal hypoglycemia rates were reported in two RWD studies [32, 35]. Exclusion of patients with recurrent severe hypoglycemia or a history of severe hypoglycemia was reported in four of the RCTs. Among RCTs, one RCT had the highest rates of hypoglycemia in all hypoglycemia categories, together with the lowest average end-of-trial $\mathrm{HbA}_{1 \mathrm{c}}$ (for patients who maintained the $\mathrm{HbA}_{1 \mathrm{c}}$ goal) [39]. However, no other trends linking hypoglycemia rates and average end-of-trial $\mathrm{HbA}_{1 \mathrm{c}}$ levels were apparent.

\section{T2DM Basal-Bolus Therapy}

Three RWD studies [32, 37, 38] and four RCTs [48-51] that reported hypoglycemia rates in T2DM patients receiving basal-bolus insulin regimens were identified in the literature search (Table 2; Supplementary Table III). As for T2DM basal-oral therapy, there was variability in reported rates across hypoglycemia categories and a large degree of overlap between the RWD studies and RCTs. The highest rates of severe and non-severe hypoglycemia were observed in RWD studies, whereas the highest rate of nocturnal hypoglycemia was observed in an RCT (Table 2; Fig. 2). Annual non-severe rates ranged from 2.95 to 38.9 episodes PPY in RWD studies vs 9.28-26.6 episodes PPY in RCTs. Severe hypoglycemia rates ranged from 0.00 to 0.2 episodes PPY in RWD studies and from 0.05 to 0.06 episodes PPY in RCTs. Nocturnal confirmed hypoglycemia event rates ranged from 0.42 to 8.5 episodes PPY in RWD studies vs 1.39-10.34 episodes PPY in RCTs. Three of the RCTs excluded patients with a history of severe hypoglycemia. In this patient population, in the RCT setting, the highest 
rates of hypoglycemia for each category came from different RCTs, and there was no correlation with end-of-trial $\mathrm{HbA}_{1 \mathrm{c}}$ levels. Diurnal non-severe hypoglycemia rates were reported in one RWD study [38] and one RCT [49] and were almost threefold higher in the RWD study. Non-severe nocturnal rates were reported in one RWD study [32].

\section{T2DM Premix Insulin}

The search identified five RWD studies $[32,37$, 52-54] and five RCTs [39, 48, 50, 51, 55] that reported hypoglycemia event rates for T2DM patients receiving a premixed insulin regimen (Table 2; Supplementary Table IV). Hypoglycemia event rates were variable across studies reporting premixed insulin regimens, and the range observed across RWD studies was very similar to that observed in RCTs (Table 2; Fig. 2). Non-severe hypoglycemia event rates ranged from 1.04 to 27.0 episodes PPY in RWD studies and from 7.08 to 20.8 episodes PPY in RCTs. Annual rates for severe hypoglycemia in RWD studies ranged from 0.00 to 0.2 episodes PPY compared with 0.03 and 0.26 episodes PPY in two RCTs. Annual rates of nocturnal confirmed hypoglycemia were $0.20-7.3$ episodes PPY in RWD studies vs 2.5-8.15 episodes PPY in RCTs. Three of the RCTs excluded patients with a history of severe hypoglycemia.

\section{DISCUSSION}

Although the results from large-scale RCTs have conventionally been used to inform clinical practice and reimbursement decisions, RWD are now being recognized as a valuable additional tool to inform current practice and future research and development [19]. Advantages of clinical trials include the prospective design, pre-specified outcomes, randomization, blinding and control groups, all of which can contribute to the generation of solid evidence under carefully controlled conditions. However, the extrapolation of results from these studies into clinical practice is challenging and may not be fully representative of a general diabetes population. Clinical trials of diabetes populations usually exclude patients with severe hypoglycemia, recurrent episodes of hypoglycemia or hypoglycemia unawareness, and the true incidence of hypoglycemia may be underestimated. Patients with renal dysfunction or elderly frail patients may also be under-represented in clinical trials. Diabetes patients with renal dysfunction are at an increased risk of hypoglycemia as many antidiabetic drugs are renally excreted [56]. Similarly, older ( $>75$ years) people may have a tendency toward hypoglycemia due to malnutrition and comorbidities [57]. In addition, patients enrolled in RCTs are usually subjected to more intensive monitoring and support than patients in routine clinical practice.

There are well documented limitations of RWD, such as the potential for bias with non-randomized data and inconsistent data collection. However, guidelines have been developed to provide more uniformity for such studies [58] and the value of observational research is being increasingly recognized. Real-world data are essential for informed reimbursement decisions and different study designs can provide relevant information in different situations [21]. Although RCTs remain the gold standard for demonstrating clinical efficacy in restricted trial setting, other study designs can contribute to the comprehensive evidence base required for healthcare decision makers.

This study compared the annual hypoglycemia event rates of insulin-treated 
patients with T1DM and T2DM in studies conducted in a real-world setting with those reported in a clinical trial setting.

In patients with T1DM, for all reported categories of hypoglycemia (severe, non-severe, and nocturnal), rates were higher in the RWD studies than the RCTs, with no overlap in rates between RCT and RWD settings. The two RWD studies with the highest rates of hypoglycemia were specifically designed to investigate hypoglycemia.

The rates of all categories of hypoglycemia in patients with T2DM were lower than those observed in patients with T1DM, as would be expected. In patients with T2DM receiving a basal-oral therapy regimen, there was overlap in reported hypoglycemia rates between RCTs and RWD studies; however, the highest rates of hypoglycemia, for all categories, were observed in a real-world setting. The RWD study with the lowest reported hypoglycemia rates recorded hypoglycemic events as adverse drug reactions only, rather than a pre-defined outcome [33]. The RWD study [32] that reported higher rates was a retrospective study specifically designed to investigate the frequency of non-severe and severe hypoglycemia in patients with diabetes in seven European countries [32]. As this study was designed to record hypoglycemic events, it is more likely to be an accurate reflection of the frequency of hypoglycemia in patients with diabetes.

In T2DM patients receiving a basal-bolus insulin regimen, the highest rates of severe and non-severe hypoglycemia were observed in RWD studies, whereas the highest rate of nocturnal hypoglycemia was observed in an RCT. Although again, there was a large degree of overlap in reported rates between the RWD studies and the RCTs. Only one of the five RCTs in this group reported the rate of severe hypoglycemia, the remainder simply reported number of patients who experienced a severe event; this is likely due to the low number of severe events in these studies. The higher rate of nocturnal hypoglycemia in the RCTs was driven by one study, an insulin intensification study [48].

With respect to studies reporting premix regimens in patients with $\mathrm{T} 2 \mathrm{DM}$, annual rates of hypoglycemic events were variable across all included studies, and the range was similar for RWD studies and RCTs.

For the purposes of this study, we considered three categories of hypoglycemia-severe, non-severe and nocturnal. However, there was inconsistency in the definitions of hypoglycemia between individual studies. For example, some RCTs defined confirmed hypoglycemic events as a blood glucose level $<3.1 \mathrm{mmol} / \mathrm{L}$ (RCTs, $n=14$; RWD, $n=7$ ) and in other studies, a blood glucose level $<3.9 \mathrm{mmol} /$ L with or without symptoms (RCTs, $n=4$; RWD, $n=2$ ) was considered a confirmed or mild/moderate event. Although the American Diabetes Association (ADA) definition of hypoglycemia is a blood glucose concentration $<3.9 \mathrm{mmol} / \mathrm{L}$ [9], there is no consensus definition of a threshold level at which hypoglycemia is diagnosed; thresholds from $<3.9$ to $<3.0 \mathrm{mmol} / \mathrm{L}$ have also been defined [18]. Blood glucose levels often fall below $3.9 \mathrm{mmol} / \mathrm{L}$ in healthy individuals; hence, levels of $3.5-4.0 \mathrm{mmol} / \mathrm{L}$ are unlikely to be of clinical significance $[18,59]$. Many RWD studies defined non-severe events as self-treated, with or without a blood glucose measurement. Furthermore, many studies reported confirmed hypoglycemia, which included both severe and non-severe events, and in some cases nocturnal hypoglycemia. Thus, mutually exclusive groups could not be defined. We saw no obvious patterns between hypoglycemia definition and event rates in our review, in that the rates were not higher in those studies that used the higher 
blood glucose threshold of $<3.9 \mathrm{mmol} / \mathrm{L}$; nevertheless, these caveats should be considered when interpreting these data. It is also important to consider $\mathrm{HbA}_{1 \mathrm{c}}$ targets as more stringent targets may explain higher hypoglycemia event rates.

Severe hypoglycemia by its very nature carries the risk of injury and can even be life-threatening to a patient with diabetes if not managed promptly [60]. Thus, it is considered an important and dangerous complication of diabetes. Although non-severe hypoglycemia occurs more frequently than severe hypoglycemia in both T1DM and T2DM, the incidence and importance of non-severe hypoglycemia are frequently underestimated. As many non-severe hypoglycemic events can be asymptomatic, they may go unnoticed by the patient [61]. In addition, some patients may not consider a non-severe event significant enough to be reported to their treating physician [32]. It is therefore likely that many incidences of non-severe hypoglycemia go unreported in the real world. The RWD study by Ostenson et al. reported that $65 \%$ of patients with T1DM and $50-59 \%$ of patients with T2DM either rarely or never reported their hypoglycemia events to their treating physician [32]. Some patients may refrain from disclosing the frequency or severity of their hypoglycemia for fear of losing their job or driving license [62]. Others may deliberately under-report events to their physician in case they are perceived as being unable to control their diabetes [18]. Episodes of nocturnal hypoglycemia may also have been under-reported in some studies as these events may go unnoticed by patients and their families. Hypoglycemia unawareness is the failure to recognize the onset of hypoglycemia or the complete absence of any warning symptoms [9]. This can also result in lower reported rates of hypoglycemia. Recurrent episodes of hypoglycemia increase the risk for the development of hypoglycemia unawareness [60]. Unless a study has been designed to record all categories of hypoglycemic events, it is likely that hypoglycemia event rates will be under-reported. A final consideration is that studies utilizing self-reporting of hypoglycemic events may be subject to recall bias.

When assessing full-text citations for potential inclusion in the current study, it was observed that the majority of studies that did report hypoglycemia incidence only reported the proportion of patients experiencing the event rather than actual event rates. Studies that report only the percentages of patients experiencing a hypoglycemic event cannot be used to estimate the true incidence of hypoglycemia as they do not provide any information regarding the actual frequencies of the events themselves. While there is no standard convention for the reporting of hypoglycemia events in clinical studies, the ADA Workgroup on Hypoglycemia recommends that diabetes studies report both hypoglycemia event rates and the proportion of patients experiencing the event [9].

It is also important to consider whether hypoglycemia is reported as a primary outcome in the study. RCTs often only report hypoglycemic events when they occur as adverse reactions to the study drug under investigation rather than as a primary outcome. Non-severe hypoglycemic events are often not recorded, making it difficult to estimate the true incidence of hypoglycemia in a trial population.

With respect to limitations of the data, this study was intended only as an observational analysis and focused on RCTs and RWD studies that reported the annual frequencies of hypoglycemia events in patients with T1DM 
and T2DM. No formal statistical analysis of the data was conducted. The study was not designed to determine average hypoglycemia event rates in populations with diabetes, but rather to compare hypoglycemia event ranges reported in real-world and clinical trial settings. In addition, during the literature search, no restrictions were placed on the duration of diabetes, intensity of insulin regimens, or consideration of the duration of insulin therapy, all of which have been shown to impact the frequency of hypoglycemia in patients with diabetes. For example, the UK Hypoglycaemia Study Group reported that patients with $>15$ years duration of T1DM experienced higher rates of severe hypoglycemia compared with patients with $<5$ years duration of T1DM [8]. The study also reported that longer duration of insulin treatment ( $>5$ years) was associated with increased rates of mild hypoglycemia in T2DM patients compared with those with shorter duration of insulin treatment [8].

It should also be noted that study design and how the data were collected could influence the results. For example, a retrospective analysis is likely to underestimate the true incidence of hypoglycemic events, compared with a prospective study. Similarly, there might be differences in results depending on whether the data were derived from patient diaries, or whether they were based on the results of continuous glucose monitoring.

\section{CONCLUSION}

In summary, a comparison of annual hypoglycemia event rates in patients with diabetes receiving insulin treatment showed that in patients with T1DM and T2DM (basal-oral and basal-bolus regimens) higher rates of hypoglycemia are observed in real-world settings compared with clinical trial settings, although there is a large degree of overlap in T2DM. Due to the rigorous restraints of RCT study designs, it is difficult to accurately estimate the frequency of hypoglycemia in diabetes. Consequently, the use of hypoglycemia data from RCTs of insulin-treated patients with diabetes may not be an accurate reflection of the true burden of hypoglycemia in clinical practice. There is clearly a need for further high-quality RWD studies to confirm the findings of the current review and to more accurately determine the rates of hypoglycemia in the real world. Observational studies of diabetes conducted in a real-world environment can provide valuable data regarding the use of a drug in clinical practice as treatment is monitored under real-life conditions rather than under the stringent restraints of an RCT. Supplementing efficacy data generated from RCTs with data collected in real-world settings can further demonstrate the value of new medicinal products and ultimately improve healthcare delivery to the patient.

\section{ACKNOWLEDGMENTS}

Sponsorship and article processing charges for this study were funded by Novo Nordisk A/S. Novo Nordisk contributed to the study design, data interpretation and manuscript preparation.

All named authors meet the International Committee of Medical Journal Editors (ICMJE) criteria for authorship of this manuscript, had access to data, and take responsibility for the integrity of the work as a whole, and have given final approval for the version to be published. 
Disclosures. L. Elliott and T. Stissing are employees of Novo Nordisk A/S. C. Fidler and A. Ditchfield have nothing to disclose.

Compliance with Ethics Guidelines. This article does not contain any new studies with human or animal subjects performed by any of the authors.

Open Access. This article is distributed under the terms of the Creative Commons Attribution-NonCommercial 4.0 International License (http://creativecommons.org/licenses/ by-nc/4.0/), which permits any noncommercial use, distribution, and reproduction in any medium, provided you give appropriate credit to the original author(s) and the source, provide a link to the Creative Commons license, and indicate if changes were made.

\section{REFERENCES}

1. Campbell RK, Martin TM. The chronic burden of diabetes. Am J Manag Care. 2009;15(9 Suppl):S248-54.

2. Diabetes UK. Diabetes: facts and stats. 2014. http:// www.diabetes.org.uk/Documents/About\%20Us/ Statistics/Diabetes-key-stats-guidelines-April2014. pdf. Accessed 3 Feb 2016.

3. The Diabetes Control and Complications Trial Research Group. The effect of intensive treatment of diabetes on the development and progression of long-term complications in insulin-dependent diabetes mellitus. The Diabetes Control and Complications Trial Research Group. N Engl J Med. 1993;329(14):977-86.

4. United Kingdom Prospective Diabetes Study (UKPDS). Intensive blood-glucose control with sulphonylureas or insulin compared with conventional treatment and risk of complications in patients with type 2 diabetes (UKPDS 33). UK Prospective Diabetes Study (UKPDS) Group. Lancet. 1998;352(9131):837-53.

5. American Diabetes Association. Standards of medical care in diabetes-2014. Diabetes Care. 2014;37(Suppl 1):S14-80.
6. International Diabetes Federation (IDF) Clinical Guidelines Task Force. Global guideline for Type 2 diabetes. 2012. http://www.idf.org/globalguideline-type-2-diabetes-2012. Accessed 3 Feb 2016.

7. Inzucchi SE, Bergenstal RM, Buse JB, Diamant $\mathrm{M}$, Ferrannini E, Nauck $M$, et al. Management of hyperglycemia in Type 2 diabetes, 2015: a patient-centered approach: update to a position statement of the American Diabetes Association and the European Association for the Study of Diabetes. Diabetes Care. 2015;38(1):140-9.

8. UK Hypoglycaemia Study Group. Risk of hypoglycaemia in types 1 and 2 diabetes: effects of treatment modalities and their duration. Diabetologia. 2007;50(6):1140-7.

9. American Diabetes Association Workgroup on Hypoglycemia. Defining and reporting hypoglycemia in diabetes: a report from the American Diabetes Association Workgroup on Hypoglycemia. Diabetes Care. 2005;28(5):1245-9.

10. Brod M, Christensen T, Thomsen TL, Bushnell DM. The impact of non-severe hypoglycemic events on work productivity and diabetes management. Value Health. 2011;14(5):665-71.

11. Graveling AJ, Frier BM. Impaired awareness of hypoglycaemia: a review. Diabetes Metab. 2010;36(Suppl 3):S64-74.

12. Davis RE, Morrissey M, Peters JR, Wittrup-Jensen K, Kennedy-Martin $\mathrm{T}$, Currie CJ. Impact of hypoglycaemia on quality of life and productivity in type 1 and type 2 diabetes. Curr Med Res Opin. 2005;21(9):1477-83.

13. Geelhoed-Duijvestijn PH, Pedersen-Bjergaard U, Weitgasser R, Lahtela J, Jensen MM, Ostenson CG. Effects of patient-reported non-severe hypoglycemia on healthcare resource use, work-time loss, and wellbeing in insulin-treated patients with diabetes in seven European countries. J Med Econ. 2013;16(12):1453-61.

14. Wild D, von Maltzahn R, Brohan E, Christensen T, Clauson P, Gonder-Frederick L. A critical review of the literature on fear of hypoglycemia in diabetes: implications for diabetes management and patient education. Patient Educ Couns. 2007;68(1):10-5.

15. Leiter LA, Yale JF, Chiasson JL, Harris SB, Kleinstiver $\mathrm{P}$, Sauriol L. Assessment of the impact of fear of hypoglycemic episodes on glycemic and hypoglycemia management. Can J Diabetes. 2005;29(3):186-92.

16. Hex N, Bartlett C, Wright D, Taylor M, Varley D. Estimating the current and future costs of Type 1 
and Type 2 diabetes in the UK, including direct health costs and indirect societal and productivity costs. Diabet Med. 2012;29(7):855-62.

17. Parekh WA, Ashley D, Chubb B, Gillies H, Evans M. Approach to assessing the economic impact of insulin-related hypoglycaemia using the novel local impact of hypoglycaemia tool. Diabet Med. 2015;32:1156-66.

18. Amiel SA, Dixon T, Mann R, Jameson K. Hypoglycaemia in Type 2 diabetes. Diabet Med. 2008;25(3):245-54.

19. Association of the British Pharmaceutical Industry (ABPI). The vision for real world data-harnessing the opportunities in the UK. Demonstrating value with real world data. 2015. http://www.abpi.org.uk/ our-work/library/industry/Documents/Vision-forReal-World-Data.pdf. Accessed 10 Apr 2015.

20. Annemans L, Aristides M, Kubin M. Real-life data: a growing need. 2007. https://www.ispor.org/News/ articles/Oct07/RLD.asp. Accessed 10 Apr 2015. ISPOR Connections. Uniting Science and Practice.

21. Garrison LP Jr, Neumann PJ, Erickson P, Marshall D, Mullins CD. Using real-world data for coverage and payment decisions: the ISPOR Real-World Data Task Force report. Value Health. 2007;10(5):326-35.

22. Ligthelm RJ, Borzi V, Gumprecht J, Kawamori R, Wenying Y, Valensi P. Importance of observational studies in clinical practice. Clin Ther. 2007;29(6 Pt 1):1284-92.

23. Gough SCL, Bhargava A, Jain R, Mersebach H, Rasmussen S, Bergenstal RM. Low volume insulin degludec $200 \mathrm{U} / \mathrm{ml}$ once-daily improves glycaemic control similar to insulin glargine with a low risk of hypoglycemia in insulin-naïve patients with type 2 diabetes: a 26-week, randomized, controlled, multinational, treat-to-target trial: the $\mathrm{BEGIN}^{\mathrm{TM}}$ LOW VOLUME trial. Diabetes Care. 2013;36(9):2536-42.

24. Liebl A, Prager R, Binz K, Kaiser M, Bergenstal R, Gallwitz B. Comparison of insulin analogue regimens in people with type 2 diabetes mellitus in the PREFER Study: a randomized controlled trial. Diabetes Obes Metab. 2009;11(1):45-52.

25. Suresh K, Chandrashekara S. Sample size estimation and power analysis for clinical research studies. J Hum Reprod Sci. 2012;5(1):7-13.

26. Garber AJ. Treat-to-target trials: uses, interpretation and review of concepts. Diabetes Obes Metab. 2013;16(3):193-205.

27. Bode BW, Buse JB, Fisher M, Garg SK, Marre M, Merker L, et al. Insulin degludec improves glycaemic control with lower nocturnal hypoglycaemia risk than insulin glargine in basal-bolus treatment with mealtime insulin aspart in Type 1 diabetes (BEGIN Basal-Bolus Type 1): 2-year results of a randomized clinical trial. Diabet Med. 2013;30(11):1293-7.

28. Heller S, Buse J, Fisher M, Garg S, Marre M, Merker L, et al. Insulin degludec, an ultra-longacting basal insulin, versus insulin glargine in basal-bolus treatment with mealtime insulin aspart in type 1 diabetes (BEGIN Basal-Bolus Type 1): a phase 3, randomised, open-label, treat-to-target non-inferiority trial. Lancet. 2012;379(9825):1489-97.

29. Hirsch IB, Bode B, Courreges JP, Dykiel P, Franek E, Hermansen $\mathrm{K}$, et al. Insulin degludec/insulin aspart administered once daily at any meal, with insulin aspart at other meals versus a standard basal-bolus regimen in patients with type 1 diabetes: a 26-week, phase 3, randomized, open-label, treat-to-target trial. Diabetes Care. 2012;35(11):2174-81.

30. Kristensen PL, Hansen LS, Jespersen MJ, Pedersen-Bjergaard U, Beck-Nielsen $H$, Christiansen JS, et al. Insulin analogues and severe hypoglycaemia in type 1 diabetes. Diabetes Res Clin Pract. 2012;96(1):17-23.

31. Mathieu C, Hollander P, Miranda-Palma B, Cooper J, Franek E, Russell-Jones D, et al. Efficacy and safety of insulin degludec in a flexible dosing regimen vs insulin glargine in patients with Type 1 diabetes (BEGIN: Flex T1): a 26-week randomized, treat-to-target trial with a 26-week extension. J Clin Endocrinol Metab. 2013;98(3):1154-62.

32. Ostenson CG, Geelhoed-Duijvestijn P, Lahtela J, Weitgasser R, Markert Jensen M, Pedersen-Bjergaard U. Self-reported non-severe hypoglycaemic events in Europe. Diabet Med. 2014;31(1):92-101.

33. Tsai ST, Pathan F, Ji L, Yeung VT, Chadha M, Suastika K, et al. First insulinization with basal insulin in patients with Type 2 diabetes in a real-world setting in Asia. J Diabetes. 2011;3(3):208-16.

34. Echtay A, Tsur A, Hasan MI, Abu-Hijleh MO, Al Khatib N, Andari E, et al. Clinical experience with insulin detemir in patients with type 2 diabetes from the near East countries. Diabetes Ther Res Treat Educ Diabetes Relat Disord. 2013;4(2):399-408.

35. Khunti K, Caputo S, Damci T, Dzida GJ, Ji Q, Kaiser $M$, et al. The safety and efficacy of adding once-daily insulin detemir to oral hypoglycaemic agents in patients with type 2 diabetes in a clinical practice setting in 10 countries. Diabetes Obes Metab. 2012;14(12):1129-36. 
36. Verges B, Brun JM, Tawil C, Alexandre B, Kerlan V. Strategies for insulin initiation: insights from the French LIGHT observational study. Diabetes Metab Res Rev. 2012;28(1):97-105.

37. Home $\mathrm{P}$, Naggar NE, Khamseh M, Gonzalez-Galvez G, Shen C, Chakkarwar P, et al. An observational non-interventional study of people with diabetes beginning or changed to insulin analogue therapy in non-Western countries: the A1chieve study. Diabetes Res Clin Pract. 2011;94(3):352-63.

38. Brod M, Rana A, Barnett AH. Impact of self-treated hypoglycaemia in type 2 diabetes: a multinational survey in patients and physicians. Curr Med Res Opin. 2012;28(12):1947-58.

39. Buse JB, Wolffenbuttel BH, Herman WH, Hippler S, Martin SA, Jiang HH, et al. The DURAbility of Basal versus Lispro mix 75/25 insulin Efficacy (DURABLE) trial: comparing the durability of lispro mix 75/25 and glargine. Diabetes Care. 2011;34(2):249-55.

40. DeVries JH, Bain SC, Rodbard HW, Seufert J, D'Alessio D, Thomsen AB, et al. Sequential intensification of metformin treatment in type 2 diabetes with liraglutide followed by randomized addition of basal insulin prompted by A1C targets. Diabetes Care. 2012;35(7):1446-54.

41. Meneghini L, Atkin SL, Gough SC, Raz I, Blonde L, Shestakova $M$, et al. The efficacy and safety of insulin degludec given in variable once-daily dosing intervals compared with insulin glargine and insulin degludec dosed at the same time daily: a 26-week, randomized, open-label, parallel-group, treat-to-target trial in individuals with type 2 diabetes. Diabetes Care. 2013;36(4):858-64.

42. Meneghini L, Kesavadev J, Demissie M, Nazeri A, Hollander P. Once-daily initiation of basal insulin as add-on to metformin: a 26-week, randomized, treat-to-target trial comparing insulin detemir with insulin glargine in patients with type 2 diabetes. Diabetes Obes Metab. 2013;15(8):729-36.

43. Onishi Y, Iwamoto Y, Yoo SJ, Clauson P, Tamer SC, Park S. Insulin degludec compared with insulin glargine in insulin-naive patients with type 2 diabetes: a 26-week, randomized, controlled, Pan-Asian, treat-to-target trial. J Diabetes Investig. 2013;4(6):605-12.

44. Philis-Tsimikas A, Del Prato S, Satman I, Bhargava A, Dharmalingam M, Skjoth TV, et al. Effect of insulin degludec versus sitagliptin in patients with type 2 diabetes uncontrolled on oral antidiabetic agents. Diabetes Obes Metab. 2013;15(8):760-6.

45. Rodbard HW, Cariou B, Zinman B, Handelsman Y, Philis-Tsimikas A, Skjoth TV, et al. Comparison of insulin degludec with insulin glargine in insulin-naive subjects with Type 2 diabetes: a 2-year randomized, treat-to-target trial. Diabet Med. 2013;30(11):1298-304.

46. Zinman B, Philis-Tsimikas A, Cariou B, Handelsman Y, Rodbard HW, Johansen T, et al. insulin degludec versus insulin glargine in insulin-naive patients with Type 2 diabetes: a 1-year, randomized, treat-to-target trial (BEGIN Once Long). Diabetes Care. 2012;5(35):2464-71.

47. Buse JB, Vilsboll T, Thurman J, Blevins TC, Langbakke IH, Bottcher SG, et al. Contribution of liraglutide in the fixed-ratio combination of insulin degludec and liraglutide (IDegLira). Diabetes Care. 2014;37(11):2926-33.

48. Bowering K, Reed VA, Felicio JS, Landry J, Ji L, Oliveira J. A study comparing insulin lispro mix 25 with glargine plus lispro therapy in patients with Type 2 diabetes who have inadequate glycaemic control on oral anti-hyperglycaemic medication: results of the PARADIGM study. Diabet Med. 2012;29(9):e263-72.

49. Garber AJ, King AB, Del Prato S, Sreenan S, Balci MK, Munoz-Torres $M$, et al. Insulin degludec, an ultra-long acting basal insulin, versus insulin glargine in basal-bolus treatment with mealtime insulin aspart in type 2 diabetes (BEGIN Basal-Bolus Type 2): a phase 3, randomised, open-label, treat-to-target non-inferiority trial. Lancet. 2012;379(9825):1498-507.

50. Jain SM, Mao X, Escalante-Pulido M, Vorokhobina $\mathrm{N}$, Lopez I, Ilag LL. Prandial-basal insulin regimens plus oral antihyperglycaemic agents to improve mealtime glycaemia: initiate and progressively advance insulin therapy in type 2 diabetes. Diabetes Obes Metab. 2010;12(11):967-75.

51. Miser WF, Arakaki R, Jiang H, Scism-Bacon J, Anderson PW, Fahrbach JL. Randomized, open-label, parallel-group evaluations of basal-bolus therapy versus insulin lispro premixed therapy in patients with type 2 diabetes mellitus failing to achieve control with starter insulin treatment and continuing oral antihyperglycemic drugs: a noninferiority intensification substudy of the DURABLE trial. Clin Ther. 2010;32(5):896-908.

52. Berntorp K, Haglund M, Larsen S, Petruckevitch A, Landin-Olsson $\mathrm{M}$. Initiation of biphasic insulin aspart 30/70 in subjects with type 2 diabetes mellitus in a largely primary care-based setting in Sweden. Prim Care Diabetes. 2011;5(2):89-94.

53. Pirags V, El Damassy H, Dabrowski M, Gonen MS, Racicka E, Martinka E, et al. Low risk of severe hypoglycaemia in patients with type 2 diabetes mellitus starting insulin therapy with premixed 
insulin analogues BID in outpatient settings. Int J Clin Pract. 2012;66(11):1033-41.

54. Makela JK, Schmuser C, Askonen K, Saukkonen T. Starting or switching to biphasic insulin aspart 30 (BIAsp 30) in type 2 diabetes: a multicenter, observational, primary care study conducted in Finland. Diabetes Res Clin Pract. 2012;95(1):10-8.

55. Rosenstock J, Lorber DL, Gnudi L, Howard CP, Bilheimer DW, Chang PC, et al. Prandial inhaled insulin plus basal insulin glargine versus twice daily biaspart insulin for type 2 diabetes: a multicentre randomised trial. Lancet. 2010;375(9733):2244-53.

56. Moen MF, Zhan M, Hsu VD, Walker LD, Einhorn LM, Seliger SL, et al. Frequency of hypoglycemia and its significance in chronic kidney disease. Clin J Am Soc Nephrol. 2009;4(6):1121-7.

57. Abdelhafiz AH, Rodriguez-Manas L, Morley JE, Sinclair AJ. Hypoglycemia in older people-a less well recognized risk factor for frailty. Aging Dis. 2015;6(2):156-67.
58. von Elm E, Altman DG, Egger M, Pocock SJ, Gotzsche PC, Vandenbroucke JP. Strengthening the Reporting of Observational Studies in Epidemiology (STROBE) statement: guidelines for reporting observational studies. BMJ. 2007;335(7624):806-8.

59. Swinnen SG, Mullins P, Miller M, Hoekstra JB, Holleman F. Changing the glucose cut-off values that define hypoglycaemia has a major effect on reported frequencies of hypoglycaemia. Diabetologia. 2009;52(1):38-41.

60. Seaquist ER, Anderson J, Childs B, Cryer P, Dagogo-Jack S, Fish L, et al. Hypoglycemia and diabetes: a report of a workgroup of the American Diabetes Association and the Endocrine Society. Diabetes Care. 2013;36(5):1384-95.

61. Unger J. Uncovering undetected hypoglycemic events. Diabetes Metab Syndr Obes. 2012;5:57-74.

62. Graveling AJ, Frier BM. Hypoglycaemia: an overview. Prim Care Diabetes. 2009;3(3):131-9. 